\title{
COMBINATION OF NATURALAND ARTIFICIAL FACTORS IN MAKING UP MODERN TEXTS
}

\author{
Sergey P. Kushneruk \\ Volgograd Institute of Humanities, Volgograd, Russia
}

\begin{abstract}
The paper deals with external, extralinguistic conditions and rules which together with traditional linguistic regulators determine the content, form and structure of nonfiction texts as objects of analytical-andsynthetic and technical operations associated with the storage and current use of speech objects. It is shown that along with natural rules of the modern language, nonfiction texts are under the increasing influence of direct instructions and / or the derivatives from rules and requirements formulated beyond the speech regulation process, i.e. beyond linguistics. The external regulating actions not only determine the form and content of communicative means, but also change the general composition and sense of applied linguistics' tasks. Substantial and methodological changes of applied linguistics' interests depending on such factors as changes of the legal, social and economic environment are shown. Development of the factors mentioned above, is the basis for the rules which implementation demands the change of steady used speech-building principles; in some cases changes have ambiguous character if to look at them from the viewpoint of communicative traditions realized in the speech. The research of similar situations by the means of applied linguistics' methods and receptions taking the opportunity of high methodological mobility and confirmed effectiveness of natural-science and engineering resources' attraction has both exceptional sense and forecasting prospect.

Key words: applied linguistics, scientific-and-technical and documentary texts, text-making rules, communicative conditions, unification and standardization of speech objects, extralinguistic communicative conditions, formal textual regulation.
\end{abstract}

Citation. Kushneruk S.P. Combination of Natural and Artificial Factors in Making up Modern Texts. Vestnik Volgogradskogo gosudarstvennogo universiteta. Seriya 2, Yazykoznanie [Science Journal of Volgograd State University. Linguistics], 2018, vol. 17, no. 3, pp. 16-23. (in Russian). DOI: https://doi.org/10.15688/jvolsu2.2018.3.2

\section{ЕСТЕСТВЕННОЕ И ИСКУССТВЕННОЕ В СОЗДАНИИ ТЕКСТОВ СОВРЕМЕННОЙ КОММУНИКАЦИИ}

\section{Сергей Петрович Кушнерук}

Волгоградский гуманитарный институт, г. Волгоград, Россия

\footnotetext{
Аннотация. В статье рассматриваются внешние, нелингвистические условия и правила, которые в совокупности с традиционными интралингвистическими регуляторами определяют содержание, форму и состав нехудожественных текстов - объектов аналитико-синтетических и технических операций, связанных $\underset{\sigma}{\circ}$ с хранением и текущим использованием речевых объектов. Показано, что наряду с естественными дейс ствиями правил современного языка, нехудожественные тексты испытывают все большее влияние прямых предписаний и / или производных от правил и требований, сформулированных за пределами речевого ๖ регулирования. Внешние регулирующие действия не только определяют облик и содержание коммуникативных средств, но и изменяют состав и характер задач прикладной лингвистики. Описаны их содержательные и методологические преобразования в зависимости от факторов правовой и социально-экономической среды. Показано, что развитие этих факторов формирует правила, реализация которых требует трансформа(2) ции устойчивых речевых решений; в ряде случаев изменения имеют неоднозначный характер с точки зрения
} 
коммуникативных традиций языка. Исследование подобных ситуаций с использованием приемов и методов прикладной лингвистики с ее высокой методической мобильностью и подтвержденными возможностями привлечения естественнонаучных и инженерных ресурсов имеет как частный прагматический смысл, так и прогностическую перспективу.

Ключевые слова: прикладная лингвистика, научно-технические и документные тексты, правила создания текстов, условия коммуникации, унификация и стандартизация речевых объектов, экстралингвистические условия коммуникации, формальное текстовое регулирование.

Цитирование. Кушнерук С. П. Естественное и искусственное в создании текстов современной коммуникации // Вестник Волгоградского государственного университета. Серия 2, Языкознание. - 2018. - Т. 17 , № 3. - C. 16-23. - DOI: https://doi.org/10.15688/jvolsu2.2018.3.2

Изъ чтенія актовъ и дьловыхъ бумагъ вообще мы усматриваемъ троякій дъловой слогъ: 1) установленный закономъ; 2) введенный прежнимъ канцеляркским и д қловымъ обычаемъ и 3) новый д女ловой слогъ, образовавшійся преимущественно въ наше время въ министерствахъ и другихъ государственныхъ установленіяхъ.

Н.В. Варадинов. Делопроизводство (СПб., 1857)

\section{Задачи прикладной лингвистики: развитие состава}

Весьма условное противопоставление содержания терминов «теоретическая лингвистика» и «прикладная лингвистика» строится в том числе на появлении в какой-то период времени некоего внешнего вызова, совокупности проблемных ситуаций, не лингвистических по своей общей содержательной направленности, но предполагающих реализацию в жесткой последовательности технологических операций обязательной компоненты, имеющей исключительно лингвистическое содержание. Примером может служить формирование и решение большого класса задач, связанных, например, с разработкой автоматизированных систем информационного поиска (АИПС) в 60-70-е гг. прошлого века: процессы создания и применения поисковых языков регулировались не только правилами и принципами, «созревшими» в лингвистике того времени, но и требованиями, производными от применяемых компьютерных технологий, программных ограничений, поисковых стратегий и алгоритмов.

Из методических соображений существование и развитие прикладной лингвистики можно описать упрощенной формулой. Об- щественный прогресс порождал технические, социально-бытовые, экономико-правовые задачи, которые невозможно было оставить без решения. Они актуальны, связаны с естественным развитием человеческих знаний и умений, а также социально значимы. При этом в содержание этих задач входят коммуникативные компоненты. Иногда само наличие «чегото лингвистического» представители «белой кости» - доминирующего научно-практического направления - воспринимают как второстепенное составляющее с архаичным и малозначащим содержанием ${ }^{1}$.

Bce, о чем мы будем говорить ниже, не имеет отношения к речевым объектам (текстам), создаваемым и используемым в сфеpax публицистики, художественного творчества и разговорно-бытового общения, а касается текстов официально-деловых и, в некоторой степени, научно-технических, поскольку они требуют рассмотрения в связи с явно изменившимися условиями их порождения и функционирования.

\section{Корреляция}

\section{экстралингвистических условий с содержанием}

лингвистической методологии

Общее направление развития прикладной лингвистики с 50-х гг. прошедшего века хорошо прослеживается. Актуальными были задачи разработки поисковых языков, внедрения тезаурусных технологий и совершенствования аналитико-синтетических операций, в которых научно-технические тексты являлись основными объектами. Это обстоятельство определяло содержательный мэйнстрим прикладной лингвистики до середины 80-х годов. В разных аспектах успешно 
исследовалась специфика терминообразования, терминологической типологии, терминологической лексикографии, системно-семантические организации терминосистем и логико-семантические особенности знаковых средств при создании искусственных языков для формализованных коммуникативных и аналитических систем ${ }^{2}$.

Ряд социальных изменений, стремительных и неоднозначных в своем содержании, начавшихся в заключительные десятилетия прошедшего века, несколько изменил фокус лингвистических интересов. В некоторых важнейших направлениях, которые формируют основополагающие условия существования общества, происходили и до сих пор происходят содержательные трансформации, в результате которых возникают новые или радикально изменяются уже имеющиеся коммуникативные инструменты. Здесь речь может идти не только о документных текстах, которые представляют сведения в регламентированных формах и являются коммуникативными инструментами, связанными с государственным и региональным управлением, правом, экономикой, но и о новых в типологическом отношении текстах, появляющихся в рекламной коммуникации, в Public Relations, о текстах, имеющих межжанровый статус и являющихся речевым представлением таких, например, мероприятий, как международные специализированные форумы (например, Петербургский экономический форум, Давосский экономико-политический форум). Деформализация антуража, произвольность коммуникативного поведения и свобода выбора знаковых средств в принятых коммуникативных условиях способствовали созданию текстов, формы и состав речевых средств которых заметно отличаются от аналогичных параметров классических, «стилистически верных» речевых продуктов.

\section{Условия и ограничения развития прикладной лингвистики}

Вышесказанное порождает вопрос: в какой степени изменяющиеся условия создания коммуникативных инструментов, а именно воздействие факторов интралингвистической и экстралингвистической природы - влияют на состав задач, которые должны разрешаться в координатах прикладной лингвистики. При этом следует понимать, что и содержательные координаты прикладной лингвистики изменяются. Степень и направление этих трансформаций определяются развитием лингвистической теории, изменением состава задач, рассматриваемых социумом как актуальные, методическими и технологическими возможностями (часто связанными не с лингвистикой, а с сопряженными предметными сферами естественнонаучного содержания), с ограничениями и содержанием регуляторов речевых реализаций и даже с некоторой модой, отражающей гипертрофированные социальные представления об актуальности и важности задач, включающих лингвистические составляющие.

Рассмотрим некоторые из перечисленных факторов.

Развитие лингвистической теории. Если максимально упростить содержание этого тезиса, то возникнет необходимость ответить на вопрос: как изменения теоретических представлений в области лингвистики влияют на решение практических задач, требующих вмешательства лингвиста?

Размышляя над содержательными параметрами лингвистической науки начала XXI в., О.Г. Ревзина исходит из того, что теоретическая лингвистика нашего века ориентирована на построение целостной теории языка, которая предполагает накопления и многомерные систематизации лингвистических явлений, расширение и детализацию дискурсивного анализа языковых единиц в их содержательном и стилевом разнообразии, анализ отношений между текстами разного состава и разных назначений [Ревзина, 2004]. Как видим, состав проблем не сводится к перечню частных теоретических задач, но организует комплексные описания, которые имеют вид модели действий с нечеткими границами этапов и содержанием конкретных теоретических операций.

По нашему мнению, для актуального спектра прикладных задач значимыми являются результаты теоретических исследований в следующих областях. Во-первых, необходим анализ общих тенденций, связанных с изменениями условий и организации построения 
речевых продуктов. Эти исследования обеспечили бы обоснования создания релевантных текстовых объектов. Во-вторых, актуализируется такая теоретическая задача, как построение модели функциональных соответствий текстов. Очевидно, это направление является одним из направлений общей теории текста. В-третьих, более глубокого анализа требуют типовые коммуникативные ситуации с учетом изменений в их составе и в правилах реализации.

Состав актуальных задач. Этот тезис, точнее, видение его содержания может вызвать бурную дискуссию. Она будет обусловлена самими качествами прикладной лингвистики: множественностью частных задач со своими группами адептов, прагматикой ситуаций. Осторожное по степени своего обобщения и восходящее к представлению В.А. Звегинцева соображение о том, что задачи прикладной лингвистики связаны с оптимизацией функции языка, приемлемо, если как удовлетворительное рассматривается некое общее представление о круге актуальных задач. Остальное - на усмотрение, но такое «усмотрение» связано с частными задачами, которые возникают в предметных областях, имеющих лингвистическую компоненту.

Безусловно, круг задач, подлежащих постановке и решению, как минимум, не сужается. Более того, растет состав дисциплин, обнаруживающих свою связь с лингвистикой и, соответственно, с необходимостью привлечения специалистов, которые должны разобраться в лингвистических аспектах некой специфической деятельности, ярким, но не единственным примером которой может служить экспертная деятельность - работа лингвистов, проводящих досудебные и судебные экспертизы и их исследование [Баранов, 2017]. Растущее число клиентских обращений, развитие содержательного разнообразия научных изысканий в этой области демонстрируют не только эффективность лингвистических операций, но и экспликативные возможности речевого материала, а также продуктивность некоторой совокупности лингвистических действий, результаты которых получают важные интерпретирующие качества в координатах юриспруденции.
Документные стандарты и прикладная лингвистика; юридическая лингвистика. Еще одним примером расширения круга актуальных задач прикладной лингвистики является уровень внимания к совершенствованию лингвистических технологий, ориентированных на тексты, формы, состав и функции которых связаны с официально-деловой коммуникацией (ОДК) ${ }^{2}$. Содержательный спектр собственно лингвистических подзадач при названных объектных условиях и широк, и противоречив. При работе с текстами ОДК иногда сложно понять, где заканчивается лингвистика и начинается что-то внешнее, относящееся, например, к области формализации и классификации понятий, к нахождению унифицирующих оснований. Более того, состав лингвистических задач будет наверняка изменяться под влиянием внешних факторов. Стремительная (по меркам естественного языкового развития) смена стандартов, которые определяют из-за пределов лингвистики формы и составы документных текстов, практически не обусловлена качественными параметрами инструментов ОДК, естественными коммуникативными потребностями. Последние стандарты на организационно-распорядительные документы регулировали, с точки зрения лингвистики, малозначащие нюансы, однако эти нюансы текстов, видимо, были принципиальными для сопряженной предметной деятельности. Стандарт на организационно-распорядительные документы 1997 г. был заменен очередным стандартом в 2003 г. (срок действия - 6 лет). Эта стремительная замена могла бы рассматриваться как обусловленная известными социально-правовыми преобразованиями. Основания очередной замены стандарта 2003 г. другим, введенным с июля 2018 г., можно найти, однако они вряд ли имеют однозначный и непременный характер [ГОСТ Р 6.30-97; ГОСТ Р 6.30-2003; ГОСТ Р 7.0.97-2016]. Есть причина полагать, что так называемая документная лингвистика с ее объектной спецификой и пристальным вниманием к связи между речевыми формами реквизитов и экстралингвистическими регуляторами их составов является одним из разделов «новой» прикладной лингвистики. Название этого раздела определяется классом объектов лингвистической деятельности. 
Технологические и методические возможности документной лингвистики. Этот раздел в значительной степени связан с дискуссионными сторонами именований, основания для которых затронуты выше. В относительно недавний период времени под влиянием всеобщей компьютеризации социума, чрезвычайного расширения классов задач, решаемых с помощью компьютеров, хорошим тоном и показателем методической «продвинутости» стало появление в учебных планах филологических специальностей дисциплины «компьютерная лингвистика». В обсуждениях обнаружилась крайняя пестрота того, как этот термин понимается, каковы его системные качества. Часто дискуссия сводилась к тому, что «компьютерная лингвистика - это использование компьютера в лингвистических исследованиях и в коммуникативной практике». Следовательно, некоторый неоднородно понимаемый якобы раздел лингвистики получил наименование по универсальному, полезному инструменту. Только внедренность предмета, соизмеримая с бытовой прозаичностью зубной щетки или ключей от квартиры, может обусловить наименование научно-практической деятельности не по ее содержанию или по объекту действий, а по инструменту.

Вышеприведенные дискуссионные соображения связаны с тем обстоятельством, что в ряде случаев термин «прикладная лингвистика» (особенно в вузах, открывших это направление, но не нашедших возможности пригласить специалистов с базовой квалификацией) рассматривается как синоним термина «компьютерная лингвистика», что методологически неверно.

Охарактеризуем классы задач, относящиеся к прикладной лингвистике, при решении которых использование компьютеров позволяет получать эффективные и относительно надежные результаты:

- построение и хранение межпредметных тезаурусов большого объема и адаптивной изменяемости состава логико-семантических отношений, их использование при универсальной обработке массивов специальных текстов, создании аналитических обзоров и рефератов, моделировании семантических отношений для локальных терминологий, совершенствовании дескрипторных составов информационно-поисковых языков (ИПЯ). Красиво назван один из аспектов этой работы завтрашнего дня: «Именованные сущности в текстах русского языка» [Можарова, Лукашевич, 2017, с. 14]; - автоматизированный перевод; явные недостатки нынешнего автоматизированного перевода свидетельствуют о сложности решаемых задач: уровень позитивности результатов в этой сфере зависит как от физических возможностей компьютерных систем, так и от совершенствования программных процессов, возможности которых пока разбиваются не столько о структурно-семантические различия языков, сколько о дискурсы, ситуативные привязки текстов, о то, что называется «окрасками» и затекстовыми особенностями, усваиваемыми не в качестве системных, языковых особенностей, а как надъязыковые «отпечатки опыта»;

- лингвистическая экспертиза; классы задач, которые, на первый взгляд, решаются прикладной лингвистикой, но в отношении надежности получаемых результатов существуют либо несовпадающие интерпретации, либо вводятся допуски, оправдываемые мотивом «что можем, то и делаем». Примеры задач этой типологической группы находим в авторских экспертизах, в задачах с некорректно или неточно заданными условиями, с полифункциональной и полисемантичной терминологией, а также в исследованиях, успех которых определяется принципом «чем больше материала, тем лучше» ${ }^{3}$. Анализ практически всего текстового наследия М.А. Шолохова, осуществленный скандинавскими учеными [Хьетсо и др., 1989], не позволил получить окончательного и определенного вывода в части авторства исследованных прозаических текстов. Да и возможен ли он при конечном объеме материала и дискуссионности реализуемых средств, в том числе - программных?..

\section{Диапазон лингвистических колебаний, вызванных внеязыковыми факторами}

Обратившись к вышесказанному, автор поймал себя на мысли, что общая окраска статьи может выглядеть пессимистичной. Фактически это не так: в настоящее время прикладная лингвистика находится в состоянии, предшествующем всплеску, содержательному взрыву. Важным фактором такой перс- 
пективы становится активизация внешних условий, правил, ограничений, порождающих, в том числе, и речевые противоречия. Именно они, изменения внешних условий и правил, но не традиционные интралингвистические регуляторы, в значительной мере управляют состояниями, составами и формами текстов. Ярким проявлением таких изменений можно считать усиление влияния на качество речевого материала унифицирующих и стандартизирующих операций. Обратим внимание на тот факт, что внешние унифицирующие правила ориентированы не только на официально-деловые тексты, но и на тексты научно-технические, например, на инструкции, регулирующие формы текста, состав разделов и знаковых средств, внешние параметры научно-технических материалов. Такие инструкции иногда представляют собой весьма объемные брошюры.

Что регулируют правила, представленные в этих брошюрах? Орфографическую, пунктуационно-грамматическую и стилистическую правильность? Нет. Мы уже не ищем, например, и ответа на вопрос, почему ссылки на цитируемое издание должны выглядеть предписываемым образом? Лингвистикой всегда хотели «поуправлять», что-то в ней немного поправить. Такие желания демонстрировали юристы, специалисты в IT, культурологи, психологи, педагоги... Список может быть продолжен. Лингвисты тоже время от времени выступали с неожиданными инициативами, имевшими странные последствия ${ }^{4}$. В связи с действием унифицирующих правил лингвистическое сообщество проявляет сложные отношения к результатам стандартизации коммуникативных процессов. Пример осторожной оценки: «Создание ГОСТов в сфере электронной коммуникации только началось, и надо признать, что пока существующие ГОСТы, унифицирующие процесс вторичного, в том числе и библиографического отражения информационных ресурсов, задачу наиболее полного представления разных видов информационных объектов решают далеко не в полной мере» [Берестова, 2017, с. 9]. Расширению регулирующих условий способствует и развитие видов деятельности, которые обслуживаются коммуникативной средой, названной А.Б. Антопольским «инфосферой». К этим видам автор относит следующие структурные составляющие исследовательской и научнопрактической деятельности: академическая, вузовская, прикладная, волонтерская (любительская) [Антопольский, 2017, с. 14]. Совершенствование алгоритмов, ориентированных на развитиеаналитико-синтетических операций, определяет содержание слабо прогнозируемой в содержательном отношении долговременной задачи, связанной с формализацией логико-содержательных операций в больших текстовых массивах [Лопатина, Зубов, Неретин, 2017].

Есть тем не менее основания надеяться на то, что прикладная лингвистика с оправданной межпредметностью, методическим развитием, интернациональными связями гармонизирует содержательные коллизии, вызванные как коммуникативными сложностями, так и воздействием внешних требований, имеющих форму стандартов и унификаторов.

\section{ПРИМЕЧАНИЯ}

${ }^{1}$ Образное именование внутренних отношений между представителями разных предметных областей, участвующих в решении междисциплинарной научно-практической задачи («черная кость) и «белая кость» - устные высказывания в рамках международной конференции документоведов), метафорически выражает иерархизированные отношения разных групп специалистов при оценке собственной значимости в ходе решения общей задачи. Одним из наиболее показательных разделений на такие группы автор вышеприведенных метафор Н.А. Храмцовская считает самооценку специалистов в области IT-технологий в процессе создания так называемых систем электронного хранения документных объектов. Естественно, специалисты-архивоведы, документоведы, менеджеры документационного обеспечения управления, создатели и редакторы документных текстов были отнесены к «черной кости», к специалистам второго ряда значимости. Подобные формы самоутверждения в некоторой степени проявлялись (и поддерживались общественным мнением) и в иных предметных сферах, например, в экономике, юриспруденции.

${ }^{2}$ По мнению автора, можно говорить о некоторой объектно-тематической периодизации прикладной лингвистики. Период 60-х - начала 80-х гг. был временем прикладной лингвистики с доминированием научно-технических текстов. «Грозди» более-менее связанных лингвистических задач были связаны именно с такими текстами, с их составом и обработкой: информационный поиск, терминове- 
дение, аналитико-синтетические преобразования, научно-технический перевод, построение тезаурусов и классификаторов, и т. д. Далее (ориентировочно со второй половины 80-х гг.) следовал период, на протяжении которого прикладная лингвистика искала себя и в методиках преподавания, и в решениях частных задач, исходящих из исследования текста, общей коммуникативистики и теории дискурca. Ряд факторов, изменивших отношение к официально-деловой коммуникации, ввел в состав доминантных объектов исследования и обработки тексты соответствующей сферы. С определенной долей условности можно говорить (с середины 90-х гг. прошедшего века) о развитии прикладной лингвистики с доминированием объектов официально-деловой коммуникации.

${ }^{3}$ Перечень задач, входящих в названные и неназванные в этом разделе исследовательские ситуации может быть значительно расширен. Для некоторых видов лингвистических задач применение мощных программно-компьютерных комплексов напоминает применение названных средств, например, в метеорологии или в исследовании физики ядерного взрыва; в областях, требующих многофакторной обработки очень больших по объему массивов. Снисходительное отношение к лингвистике, которая, как показывает связь содержаний в именовании «структурная, прикладная и математическая лингвистика», является точной наукой, обнаруживается, например, в так называемой юридической лингвистике. В юриспруденции терминоид «оскорбление чувств верующих» рассматривается как содержательно непротиворечивый. В координатах лингвистики этот фразеологизм порождает ряд вопросов. Некоторые из них: «верующих» во что?, если речь идет о религии, то как быть с верованиями, содержания которых конфликтуют или противоречат друг другу?, слово «оскорбление» по своим понятийным признакам объектно соотносится только с личностью, с субъектом, что такое оскорбление чувства»?, как можно «оскорбить чувство», если таковое является немотивированной субъективной и меняющейся реакцией?

${ }^{4}$ Примером тому может быть невнятный и неэффективный Федеральный закон от 01.06.2005 № 53-Ф3 (ред. от 05.05.2014) «О государственном языке Российской Федерации» при всех попытках его периодического совершенствования.

\section{СПИСОК ЛИТЕРАТУРЫ}

Антопольский А. Б., 2017. Инфосфера общественных наук: структура, границы, функции // Научно-техническая информация. Серия 1. Организация и методика информационной работы. № 4. С. 14-20.
Баранов А. Н., 2017. Лингвистика в лингвистической экспертизе (методика и истина) // Вестник Волгоградского государственного университета. Серия 2, Языкознание. Т. 16, № 2. C. 18-27. DOI: https://doi.org/10.15688/jvolsu2. 2017.2.2

Берестова Т. Ф., 2017. Сущностное единство библиографической информации и метаданных // Научно-техническая информация. Серия 1. Организация и методика информационной работы. № 2. С. 1-12.

ГОСТ Р 6.30-97. Унифицированные системы документации. Унифицированная система организационно-распорядительной документации. Требования к оформлению документов. М. : ИПК Изд-во стандартов, 2001 (утратил силу). URL: http://docs.cntd.ru document 871001230. docs.cntd.ru/document/. Загл. с экрана.

ГОСТ Р 6.30-2003. Унифицированные системы документации. Унифицированная система организационно-распорядительной документации. Требования к оформлению документов. М. : Стандартинформ, 2007 (принят и введен в действие постановлением Госстандарта РФ от 03.03.2003 № 65-ст) (утратил силу). URL: http://docs.cntd.ru/ document/1200031361. Загл. с экрана.

ГОСТ Р 7.0.97-2016. Национальный стандарт Российской Федерации. Система стандартов по информации, библиотечному и издательскому делу. Организационно-распорядительная документация. Требования к оформлению документов (утв. Приказом Росстандарта от 08.12.2016 № 2004-ст) (ред. от 14.05.2018). URL: http://www.consultant.ru/document/cons_doc_ LAW_216461/.Загл. с экрана.

Лопатина Н. В., Зубов Ю. С., Неретин О. П., 2017. Информационно-аналитическое обеспечение приоритетных направлений науки и техники: отраслевой и дифференцированный подходы // Научно-техническая информация. Серия 1. Организация и методика информационной работы. № 5. С. 15-21.

Можарова В. А., Лукашевич Н. В., 2017. Исследование признаков для извлечения именованных сущностей из текстов на русском языке // Научно-техническая информация. Серия 2. Информационные процессы и системы. № 5. С. 14-21.

Ревзина О. Г., 2004. Лингвистика XXI века: на путях к целостности теории языка // Критика и семиотика. Вып. 7. С. 11-20. URL: http://www. philology.ru/linguistics1/revzina-04.htm. - Загл. с экрана.

Хьетсо Г. и др., 1989. Хьетсо Г., Густавссон Г., Бекман Б., Гил С. Кто написал «Тихий Дон»?: (Проблема авторства «Тихого Дона»)/ пер. А. В. Ващенко, Н. С. Ноздриной. М. : Книга. 186 с. 


\section{REFERENCES}

Antopolskiy A.B., 2017. Infosphere of social sciences: structure, borders, functions. Nauchnotekhnicheskaya informatsiya. Seriya 1. Organizatsiya $i$ metodika informatsionnoy raboty, no. 4, pp. 14-20.

Baranov A.N., 2017. Linguistics in forensic linguistic expertise (methodology and the truth). Vestnik Volgogradskogo gosudarstvennogo universiteta. Seriya 2, Yazykoznanie [Science Journal of Volgograd State University. Linguistics], vol. 16, no. 2, pp. 18-27. DOI: https://doi.org/10.15688/ jvolsu2.2017.2.2.

Berestova T.F., 2017. Intrinsic unity of bibliographic information and metadata. Nauchnotekhnicheskaya informatsiya. Seriya 1. Organizatsiya $i$ metodika informatsionnoy raboty, no. 2, pp. 1-12.

GOST R 6.30-97. Unifitsirovannye sistemy dokumentatsii. Unifitsirovannaya sistema organizatsionnorasporyaditelnoy dokumentatsii. Trebovaniya $k$ oformleniyu dokumentov [Unified Documentation Systems. Unified System of Organizational and Administrative Documentation. Requirements for Registration of Documents]. Moscow, IPK Izd-vo standartov, 2001 (expired). URL: http:// docs.cntd.ru/document/871001230.docs.cntd.ru/ document/.

GOST R 6.30-2003. Unifitsirovannye sistemy dokumentatsii. Unifitsirovannaya sistema organizatsionno-rasporyaditelnoy dokumentatsii. Trebovaniya $k$ oformleniyu dokumentov [Unified Documentation Systems. Unified System of Organizational and Administrative Documentation. Requirements for Registration of Documents]. Moscow, Standartinform Publ., 2007 (adopted and enacted by the Resolution of the State Standard of the Russian Federation of 3 March 2003 No. 65-st) (expired). URL: http://docs.cntd.ru/document/ 1200031361.

GOST R 7.0.97-2016. Natsionalnyy standart Rossiyskoy Federatsii. Sistema standartov po informatsii, bibliotechnomu $i$ izdatelskomu delu. Organizatsionno-rasporyaditelnaya dokumentatsiya. Trebovaniya $k$ oformleniyu dokumentov (utv. Prikazom Rosstandarta ot 08.12.2016 № 2004-st) (red. ot 14.05.2018) [National Standard of the Russian Federation. System of Standards on Information, Librarianship and Publishing. Organizational and Administrative Documentation. Requirements for the Paperwork (approved by Order of Rosstandart of December 8, 2016 No. 2004-st) (ed. 05/14/2018)]. URL: http://www.consultant.ru/ document/cons_doc_LAW_216461/.

Lopatina N.V., Zubov, Yu.S., Neretin O.P., 2017. Information and analytical support for priority areas of science and technology: Branch-Dependent and Differentiated Approaches. Nauchnotekhnicheskaya informatsiya. Seriya 1. Organizatsiya i metodika informatsionnoy raboty, no. 5 , pp. 15-21.

Mozharova V.A., Lukashevich N.V., 2017. Analysis of the signs used for named objects retraction from Russian texts. Nauchno-tekhnicheskaya informatsiya. Seriya 2. Informatsionnye protsessy i sistemy, no. 5, pp. 14-21.

Revzina O.G., 2004. Linguistics of the $21^{\text {st }}$ century: on the ways to integrity of the language's theory. Kritika i semiotika [Critique and Semiotics], iss. 7, pp. 11-20. URL: http://www.philology.ru/ linguistics1/revzina-04.htm.

Hetso G., Gustavsson G., Beckman B., Gil S., 1989. The Authorship of The Quiet Don? Moscow, Kniga Publ. 186 p.

\section{Information about the Author}

Sergey P. Kushneruk, Doctor of Sciences (Philology), Professor of Department of Criminal Law Disciplines, Volgograd Institute of Humanities, Gribanova St., 12, 400011 Volgograd, Russia, sp_kushneruk@mail.ru, https://orcid.org/0000-0002-5008-3946

\section{Информация об авторе}

Сергей Петрович Кушнерук, доктор филологических наук, профессор кафедры уголовно-правовых дисциплин, Волгоградский гуманитарный институт, ул. Грибанова, 12, 400011 г. Волгоград, Россия, sp_kushneruk@mail.ru, https://orcid.org/0000-0002-5008-3946 